\section{Cari açık ve doğrudan yabancı yatırımlar arasındaki ilişki: MIST ülkeleri için ampirik bir analiz}

\section{The relationship between current deficit and foreign direct investments: An empirical analysis for MIST countries}

\author{
Serap Ürüt Saygın ${ }^{1}$
}

Öz

${ }^{1}$ Dr. Öğr. Üyesi, Aksaray Üniversitesi, İ̈BF, Maliye Bölümü, Aksaray, Türkiye serap_urut@hotmail.com

ORCID: 0000-0002-5098-375X

Başvuru/Submitted: 18/01/2021

Revizyon/Revised: 1/04/2021

Kabul/Accepted: 1/05/2021

Yayın/Online Published: 25/06/2021

Atıf/Citation: Ürüt Saygın S., Cari açık ve doğrudan yabancı yatırımlar arasındaki ilişki: MIST ülkeleri için ampirik bir analiz, bmij (2021) 9 (2): 426-438, doi: https://doi.org/10.15295/bmij.v9i2.1753
Ülkelerin karşılaştıkları birçok temel makroekonomik sorun söz konusudur. Bu sorunlar arasında cari açık sorunu serbestleşme süreci ile birlikte ülkelerin oldukça sık karşılaştıkları sorunların başında gelmektedir. Özellikle gelişmekte olan ülkelerin ara malı ithalatına bağımlılığı yüksek cari açıklar verilmesini getirmektedir. Bu açıkların giderilmesinde ise doğrudan yabancı yatırımlar (DYY) ön plana çıkmaktadır. Bu çalışmada da, cari açıklar ve doğrudan yabancı yatırımlar arasındaki ilişkinin ampirik olarak incelenmesi hedeflenmiştir. Çalışmada, 1990-2019 dönemi verileriyle MIST (Meksika, Endonezya, Güney Kore ve Türkiye) ülkeleri özelinde panel eşbütünleşme testi yapılmıştır. Analiz sonucunda değişkenler arasında uzun dönemli bir ilişki tespit edilmiştir. Uzun dönemli ilişkinin etkisini ortaya koyabilmek amacı ile de ortalama grup dinamik en küçük kareler (DOLSMG) tahmincisinden yararlanılmıştır. Analiz sonucunda incelenen ülkelerden G. Kore hariç doğrudan yabancı yatırımların cari açığı negatif yönlü etkilediği sonucuna ulaşılmıştır. Panel DOLSMG test sonucuna göre panel genelinde DYY'nin esneklik katsayıs 1.22 dir. Yani DYY'deki 1 birimlik artış cari açı̆̆ı 1.22 birim azaltmaktadır. Analizde incelenen diğer bir değişken olan ticari açıklığın ise cari açı̆̆ı arttırdığı bulgusu elde edilmiştir. Ticari açıklıktaki 1 birimlik artışın cari açığı 0.11 birim arttırdığ 1 sonucuna ulaşılmıştır.

Anahtar Kelimeler: Cari Açık, Doğrudan Yabancı Yatırım, MIST

Jel Kodlar1: C23, F21

\begin{abstract}
Countries face many fundamental macroeconomic problems. Among these problems, the current account deficit is one of the most common problems faced by countries with liberalization. Especially developing countries depend on imports of intermediate goods to cause high current account deficits. Foreign direct investments (FDI) come to the fore in eliminating these deficits. This study aims to empirically examine the relationship between the current account deficit and foreign direct investment. In the study, with data from 1990-2019, MIST (Mexico, Indonesia, South Korea and Turkey) countries have made special panel cointegration tests. As a result of the analysis, a long-term relationship was found between the variables. The mean group dynamic least squares (DOLSMG) estimator was used to reveal the effect of the long-term relationship. As a result of the analysis, it was concluded that foreign direct investments, excluding South Korea, negatively affected the current account deficit among the countries examined. According to the panel DOLSMG test result, the elasticity coefficient of FDI throughout the panel is 1.22. In other words, a 1 unit increase in FDI reduces the current account deficit by 1.22 units. In addition, it was found that trade openness, another variable examined in the analysis, increased the current account deficit. It is concluded that an increase of 1 unit in the trade deficit increases the current account deficit by 0.11 unit.
\end{abstract}

Keywords: Current Account, Foreign Direct Investment, MIST

Jel Codes: C23, F21 


\section{Extended Abstract}

\section{The relationship between current deficit and foreign direct investments: An empirical analysis for MIST countries}

\section{Literature}

With globalization, the free movement of goods and capital comes to the fore. At this point, both FDI and current account deficit are among the critical winning indicators for countries. There are many studies on these issues in the literature. However, the number of studies examining the relationship between FDI and current account deficit is relatively limited in the literature. It can be said that the number of studies on the subject has increased due to the recent increase in the current account deficit in countries and the recent prominence of the financing of FDI. Fry, Claessens, Burridge and Blanchet (1995), Mencinger (2008), Kaur, Yadav and Gautam (2012), Razmi (2009), Göçer and Peker (2014), Çeştepe, Absız and Şık (2018) and Oke and Adigun's (2020) work can be cited as examples. In general, cointegration and causality analyzes were made in the studies. There are also studies conducted with panel data analysis. In the theoretical framework, FDI is expected to affect the current account deficit negatively. The purpose of this study is to empirically examine the relationship between the current account deficit and foreign direct investments in MIST countries. There is no study examining the relationship between FDI and current account deficit for MIST countries when the literature is examined. For this reason, it is aimed to contribute to the literature by closing this gap in this study.

\section{Design and Method}

This study is a research article. The study's research question is, "Is the current account deficit affected by foreign direct investments in MIST countries?" It was determined as. The data used in the research are secondary and have been obtained from the internet database of the World Bank. In the study where panel cointegration and panel data analysis method were used, the model given in Equation 1 was used to estimate the long-term coefficients:

$$
C A B_{i t}=\propto_{0}+\beta_{1} F D I_{i t}+\beta_{2} T O_{i t}+\varepsilon_{i t}
$$

In Equation 1, CAB dependent variable, FDI argument, TO control variable, $\alpha$ is the constant coefficient, $\beta$ is the slope coefficient, and $\varepsilon$ is the error term. Here $t$ is the time, and $i$ is the country. In the study that deals with the period of 1990-2019, firstly, the cross-section dependency of the model was analyzed by the Breusch-Pagan (1980) LM test. Homogeneity tests were conducted with the delta $(\Delta)$ tests developed by Pesaran and Yamagata (2008). Then, Pesaran CADF unit root tests were carried out for the stationarities of the series. Westerlund panel cointegration tests were used to determine the existence of a long-term relationship between the series. After determining the long-term relationship, the mean group dynamic least squares (DOLSMG) method developed by Pedroni (2001) was used to determine the long-term coefficients.

\section{Findings and Discussion}

According to the Westerlund cointegration test results, it was found that there is a significant relationship between variables in the long run. When the long-term predictions among the variables were examined, the relationship between FDI and TO variables with $\mathrm{CAB}$ for the panel was consistent with the theoretical expectation. It has been determined that the changes in the FDI negatively affect the current account deficit. According to the panel DOLSMG estimator, a 1-unit increase in FDI across the panel reduces the current account deficit by 1.22 units. This is a result that supports the expectation that FDI is an essential factor in financing the current account deficit.

For this reason, the importance of countries following policies to encourage FDI entries has been explicitly demonstrated for MIST countries. The relationship between $\mathrm{TO}$ and $\mathrm{CAB}$, which is included in the analysis as a control variable, is expected to be in the same direction. According to DOLSMG results, a one-unit increase in trade deficit increases the current account deficit by 0.11 unit. Therefore, in addition to the many advantages expected with the increase in the trade deficit, it should be considered that this may cause the current account deficit problem, and notifications regarding this should be taken. When the findings are evaluated in general, it can be stated that the current account deficit is sensitive to both foreign capital investments and trade deficit. Studies with similar results in the literature; Liuyong and Yanping (2007), Mencinger (2008), Razmi (2009), Jaffri, Asghar, Mahnaz and Asjed (2012), Göçer and Peker (2014), Çeştepe, Abasız and Şık (2018) and Oke and Adigun (2020).

\section{Conclusion, Recommendation and Limitations}

According to the DOLSMG estimator, it has been determined that FDI negatively affects the current account deficit across the panel for MIST countries. Within the framework of the analysis findings, it was concluded that there is a significant interaction between the current account deficit and FDI. Therefore, the importance of FDI inflows for countries with current account deficit problems has been put forward. From this point of view, it is seen that attention should be drawn to the measures required to increase the entry of FDI into the country. FDIs care about political and economic stability in the countries they visit. Therefore, in order to increase FDI inflows, serious steps should be taken towards the realization of the necessary reforms in order to ensure this stable environment. In addition, policymakers should highlight policies that will encourage investors in FDI inflows. In addition, legal arrangements need to be made in order to reduce bureaucratic procedures. 


\section{Giriş}

Son dönemlerde ekonomi literatüründe üzerinde durulan makroekonomik göstergelerden birisi de cari açıktır. Bu göstergenin giderek daha fazla önem kazanmasının arkasında ülkelerin giderek daha fazla cari açık vermeye başlaması, bu bağlamda dışarıdan gelecek şoklar karşısında kırılganlıklarının yükselmesi ve kriz göstergelerinden biri olarak ifade edilmesi yatmaktadır. Bir ülkenin cari açık sorunu ile karşılaşmasının anlamı cari işlemlere yapılan giderlerin cari işlemlerden elde ettiği gelirlerden daha fazla olmasıdır (Erdil Şahin, 2011, ss. 48-49). Bu noktada cari açı sorunu yaşayan ülkeler cari açığın sürdürülebilmesi için çözüm önerilerine odaklanmaktadır. Çözüm noktasında ön plana çıkan faktörlerin arasında ise 1980 'lerden sonra liberalleşme ile birlikte giderek dünyada dolaşım miktarı önemli miktarda artan doğrudan yabancı yatırımlar (DYY) gelmektedir.

Doğrudan yabancı yatırımlar gittikleri ülkelere birçok açıdan etkide bulunurlar. Milli gelir, dış ticaret, istihdam ve ödemeler dengesi gibi makroekonomik değişkenler DYY'lerin etki yarattıkları alanların başlıcalarıdır. Bu alanlar arasında ödemeler dengesi bağlamında değerlendirme yapıldığında DYY'lerin cari açık üzerinde etkiler yaratacağı ifade edilebilir. DYY'ler ülkelere giriş yaptığında önemli ölçüde yatırım için sermaye getirmektedirler. Gelen sermayenin ülkeye döviz girişi sağlaması sonucunda ödemeler bilançosunun bu durumdan pozitif yönlü etkilenmesi söz konusu olur. Ayrıca DYY'ler üretim yaptıkları ülkeden yeni piyasalara açılmaları ile o ülkenin ihracatına ve ülke dışından ara malı talep etmeleri sonucu ile de ithalatına etkide bulunmaktadırlar (Polat, 2019, s. 163). Dolayısıyla DYY'lerin ödemeler bilançosu üzerinde yaratacağı etkilerin değerlendirilmesi ve cari açık sorunu yaşayan ülkeler açısından DYY'lerin çekilebilmesi için politikaların geliştirilebilmesi konusu öne çıkmaktadır.

Cari açık ve DYY üzerine yapılan çalışmalar sonucunda ülke ekonomisinin yapısı hakkında önemli bilgiler elde edilebilmektedir. Bu çalışmada da, MIST (Meksika, Endonezya, Güney Kore ve Türkiye) ülkeleri için cari açık ile doğrudan yabancı yatırımlar arasındaki ilişkinin ekonometrik olarak analiz edilmesi hedeflenmiştir. Çalışmanın dönemi 1990-2019 yılları arasıdır. 1990'lardan günümüze mal ve sermaye hareketliliğinin artması yani dünyanın giderek küresel bir hale gelmesi bu iki değişken arasındaki ilişkinin daha çok tartışılmasını getirmiştir. Literatürde bu bağlamda MIST ülkeleri için yapılmış bir çalışmaya rastlanılmadığından çalışmanın literatüre katkı sağlaması beklenmektedir.

Çalışmanın giriş bölümünü takip eden birinci bölümünde DYY ve cari açık arasındaki ilişki açıklanmaktadır. İkinci bölümde ampirik literatüre ilişkin yapılan tarama yer almaktadır. Çalışmanın üçüncü bölümünde veri seti ve model hakkında bilgi verilmektedir. Dördüncü bölümde ise çalışmanın yöntemi ve elde edilen bulgular ortaya konulmaktadır.

\section{Teorik çerçevede cari işlemler açı̆̆ı ve doğrudan yabancı yatırım ilişkisi}

Ülkelerin ekonomi politikalarında, ithal ikameci politikalardan dışa dönük politikalara geçiş ile birlikte liberalleşme eğilimleri de ön plana çıkmaya başlamıştır. 1980-1990'lı yıllardan başlayarak hemen hemen tüm ülkelerde bu serbestleşme çabaları söz konusu olmuştur. Çünkü dünya ölçeğinde bu dönemde oldukça büyük mal ve sermaye hareketliliği yaşanmıştır. Özellikle gelişmekte olan ülkelerin sermaye birikimlerinin yetersizliği ve hammadde kaynaklarındaki eksiklikler bu akımları onlar için daha önemli hale getirmiştir. Sermaye akımları içinde DYY'ler kalkınma sürecinde ülkeler için önemli bir finansman kaynağı olarak öne çıkmıştır. 1990 yılında dünyada dolaşan DYY miktarı, yaklaşık 200 milyar \$ iken bu rakam 2019 yılında 2 trilyon \$ seviyesine çıkmıştır (UNCTAD, 2020).

DYY'den finansman kaynağı işlevi yanı sıra birçok yönden gittiği ekonomiye katkı sağlaması beklenmektedir. Bunlar arasında, DYY'nin ülkeler için teknoloji yayılımı sağlaması ve bilgi getirmesi, firmaların gelişmesi ve kendini yapılandırmasında itici bir rol üstlenmesi ve rekabetin artmasında olumlu katkı sağlaması sayılabilir. Ayrıca, ülkelerin dünya ekonomisi ile bütünleşmesinde ve uluslararası ticaretin güçlendirilmesinde de DYY'nin önemli rol oynaması beklenmektedir (Borensztein, Gregoria ve Lee, 1998, ss. 116-117; Mencinger, 2008, s. 3).

DYY'ler, gittikleri ülkelerde ucuz işgücü ve hammadde avantajları elde etmek isterler. Ayrıca yeni pazarlara açılma olanaklarından da faydalanmaları, üretimlerini daha da fazla yükseltmelerinde önemli bir etken olarak ortaya konulmaktadır. Bu noktada, DYY'lerin artan üretimlerini ihracata yönlendirerek ilgili ülkenin dış ticaretinde de etkili rol oynayabileceklerini vurgulamak gerekmektedir (Göçer ve Peker, 2014, s. 90).

Cari açık, ülkelerin yaptıkları çeşitli ekonomik işlemlerin takip edildiği ödemeler bilançosunda karşılaşılan önemli bir göstergedir. Ödemeler bilançosunda yer alan cari işlemler hesabı; mal, hizmet, yatırım gelir ve gider dengesinden oluşmaktadır. Ĕger bu hesap negatif bakiye veriyorsa ekonomide cari açıı̆ın varlığı söz konusu olur. Cari açı̆̆ın varlığı ekonomilerin kırılganlıkların arttıran önemli bir 
faktördür. Dolayısıyla bu sorunu yaşayan ekonomiler için cari açı̆̆ı tolere edecek döviz girişinin elde edilmesinde DYY dikkat çekmektedir (Keskin, 2017, s. 90).

DYY, sermaye girişi sağlayarak cari açık üzerinde doğrudan etkiye sahiptir. Ayrıca, ithalat, ihracat ve kâr transferleri yolu ile de dolaylı bir etki yaratmaktadır (Bedir ve Soydan, 2016, s. 60). DYY'ler ödemeler bilançosunda finans hesabı içine kaydedilmektedir. Cari açık söz konusu olduğunda bu açık finans hesabı ile giderilir. Finans hesabında yer alan portföy yatırımları kısa vadeli sermaye akımlarından oluşmakta ve ekonomideki bir kırılganlık durumunda ülkeden hızlıca çıkabilmektedir. Bu nedenle finans hesabında bulunan DYY'ler cari açığın finansmanında sürdürülebilirlik bakımından öne çıkmaktadır (Göçer ve Peker, 2014, s. 91). DYY'lerin bu doğrudan etkisinin yanı sıra dış ticaret yoluyla dolaylı etkilerinden de bahsedilebilir. DYY'ler gittikleri ülkelerde ucuz işgücü ve hammadde yoluyla maliyet avantajı elde etmeleri sonucunda yeni piyasalara açılma gücünü elde etmektedirler. Bu açıdan bakıldığında gittikleri ülkelerden dış piyasalara açılmaları ile o ülkenin ihracatına olumlu etkide bulundukları ifade edilebilir. Ayrıca üretim sürecinde ihtiyaç duydukları bazı hammadde kaynaklarını dış dünyadan elde etmeleri sonucunda ülkenin ithalatını da etkileyebilmektedirler ki bu cari açığı olumsuz etkileyebilecek olan bir süreçtir (Polat, 2019, s. 163).

Cari açı ve DYY'ler arasındaki ilişkilerin önemi nedeniyle literatürde bu konu üzerine gittikçe daha fazla önem atfedilmektedir. Farklı ülke veya ülke grupları için çeşitli çalışmaların yapıldığı bu değişkenler arasındaki etkileşimin son dönemlerde dikkat çeken MIST ülkeleri bağlamında da ele alınması bu noktada önemsenmektedir. MIST ülkeleri gerek nüfus gerekse de ekonomik büyüklükler bağlamında yükselen ekonomiler arasında değerlendirilmektedirler. Bu ülkeler kendi bulundukları bölgelerde güçlü ekonomiler olarak konumlandırılmaktadırlar. Küresel ekonominin gelişmesinde bu ülkelerin gittikçe öneminin artması beklenmektedir (Güllü ve Yakışık, 2017, s. 240). Şekil 1'de, MIST ülkeleri için cari işlemler dengesinin GSYH'ye oranının yıllar itibariyle seyri verilmiştir.

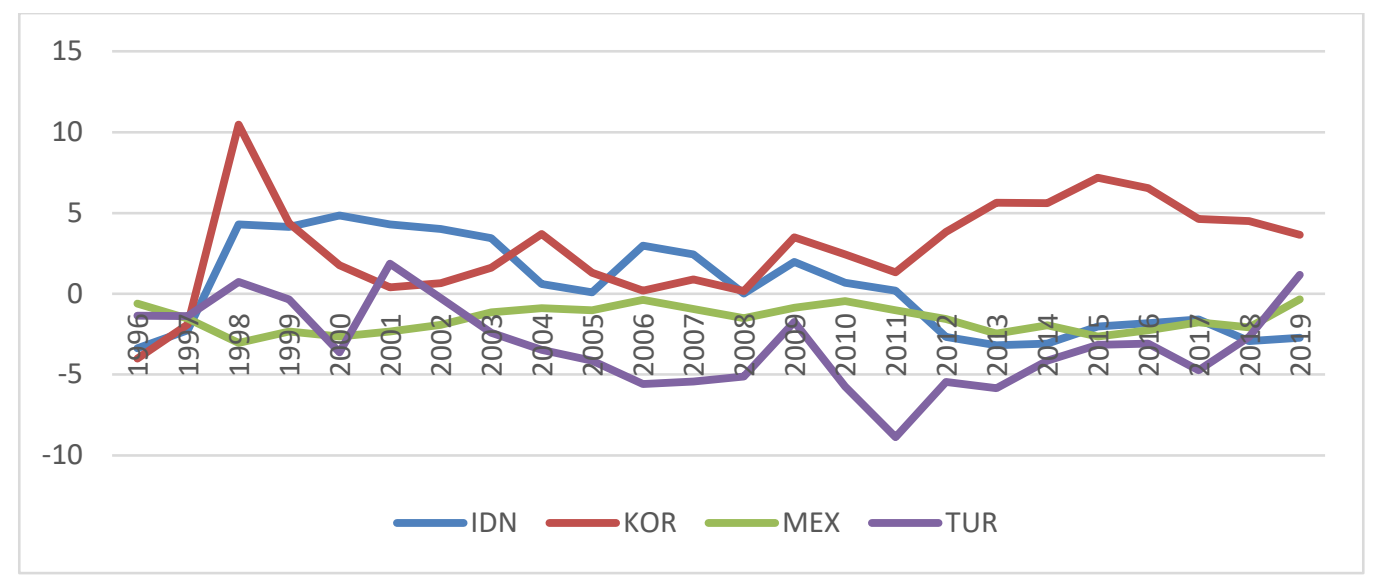

Şekil 1: MIST Ülkelerinde Cari işlemler dengesi (\% GSYH)

Kaynak: World Bank (2020) https:/ / databank.worldbank.org/source/world-development-indicators (05.12.2020).

Şekil 1 incelendiğinde, özellikle MIST ülkeleri arasında Türkiye'nin cari açık sorunu ile daha fazla karşılaştığı görülmektedir. 2000'li yıllarda ortalama \%3-5 arasında değişen oranlarda cari işlemler dengesi açık vermiştir. Ancak 2019 yılında \%1'lik bir fazla ile karşılaşılmıştır. Güney Kore'nin ise 1996 yılı hariç cari işlemler dengesinin fazla verdiği de dikkat çeken diğer bir noktadır. Endonezya'nın cari işlemler dengesinde 2000'li yıllarda cari fazla göze çarparken 2011 yılı sonrasında cari açık sorunu ile karşılaşıldığı görülmektedir. Meksika'da ise \%1-2'ler civarında yine cari açık sorunu gözlenmektedir. MIST ülkeleri için DYY'nin GSYH'deki payının değişimi ise Şekil 2'de izlenebilmektedir. 


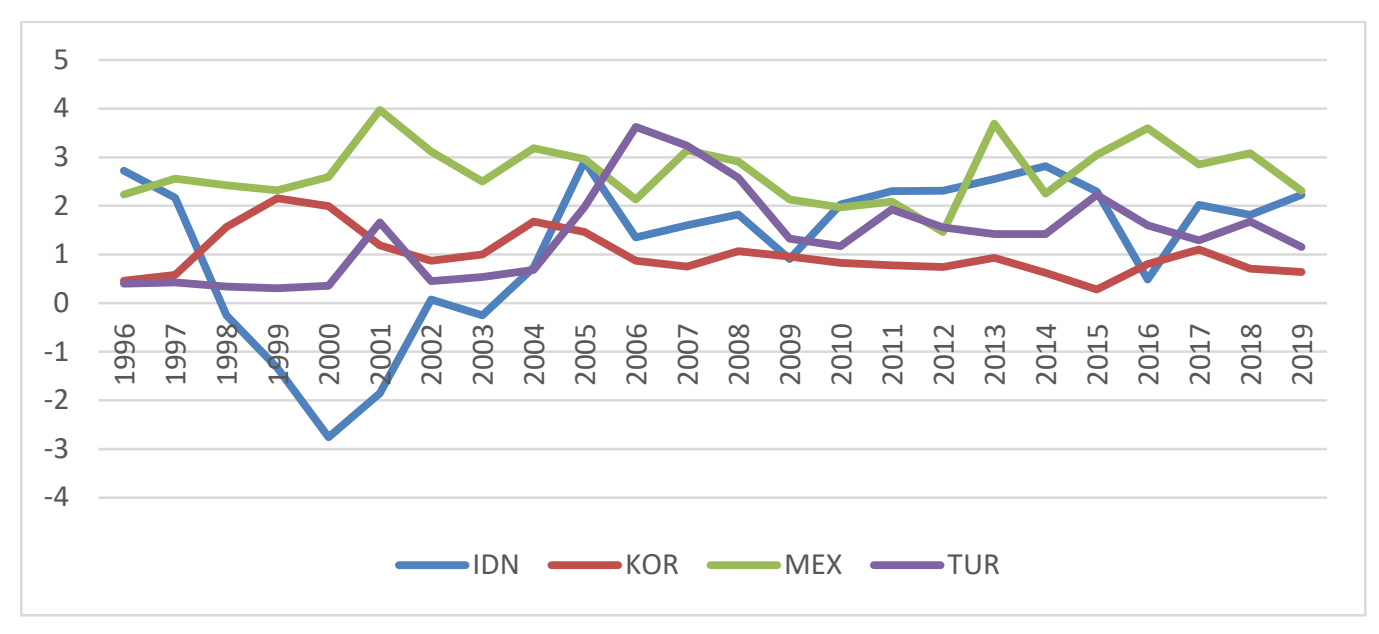

Şekil 2: MIST Ülkelerinde Doğrudan Yabancı Yatırımlar (\% GSYH)

Kaynak: World Bank (2020) https:/ / databank.worldbank.org/source/ world-development-indicators (05.12.2020).

Şekil 2 incelendiğinde Türkiye'nin DYY girişlerinin GSYH'deki payının 1996'dan 2006 yllına kadar önemli oranda artmış olduğu görülmektedir. Küresel kriz döneminde göstergede bir azalış göze çarpmakla birlikte 2010 yılı sonrasında artışlar yaşandığı da gözlenmektedir. Türkiye'de DYY'nin GSYH'deki payı 1996 yılında \%0,3 iken 2019 yılında \%1,1 olarak gerçekleşmiştir. DYY'nin GSYH'ye oranı en fazla olan ülke olarak ise Meksika görülmektedir. Meksika'da DYY'nin GSYH'deki payı 1996 yılında \%2,2 iken 2019 yılında \%2,3 olarak gerçekleşmiştir. En yüksek oranın yaşandığı yıl olan 2001 yılında ise oran \%3,9 olmuştur. Endonezya için bu oran, anılan yıllar için sırasıyla, \%2,7 ve \%2,3 olarak ifade edilebilir. Güney Kore'de ise genelde \%1'lerin altında gerçekleşen bir oran ile karşılaşılmaktadır.

\section{Ampirik literatür}

Küreselleşme ile birlikte malların ve sermayenin serbestçe dolaşımı ön plana çıkmaktadır. Bu noktada ülkeler için hem DYY hem de cari açık oldukça önemli kazanan göstergeler arasında yer almıştır. Literatürde bu konular üzerine ayrı ayrı çok sayıda çalışma yapılmıştır. Ancak literatürde DYY ve cari açık arasındaki ilişkiyi analiz eden çalışma sayısı göreceli olarak sınırlı kalmıştır. Son dönemlerde, ülkelerde yaşanan cari açığın artması ve bunun finanse edilmesinde DYY'nin ön plana çıkması ile birlikte konu ile ilgili çalışmaların sayısının arttığı söylenebilir. Çalışmalarda genellikle, eşbütünleşme ve nedensellik analizleri üzerine analizler yapılmıştır. Ayrıca panel veri analizleri ile de yapılan çalışmalar da söz konusudur. Literatür incelendiğinde MIST ülkeleri için DYY ve cari açık ilişkisini inceleyen bir çalışmaya rastlanılmamıştır. Bu nedenle bu çalışmada bu açığın kapatılarak literatüre katkı sağlanması amaçlanmıştır.

DYY ve cari açık arasındaki ilişkiyi inceleyen çalışmalardan Fry, Claessens, Burridge ve Blanchet (1995) çalışmalarında, 46 GOÜ için 1970-1992 dönemini ele almışlardır. Çalışmada, cari açı ile DYY arasındaki ilişki Granger nedensellik testi ile analiz edilmiştir. Çalışma sonucunda, birçok ülke için DYY ve cari açık arasında nedensellik ilişkileri tespit edilmiştir. Liuyong ve Yanping (2007) 1983-2005 dönemi verileri ile Çin için DYY ve cari işlemler hesabı arasındaki ilişkiyi tespit edebilmek amacıyla bir analiz yapmışlardır. Sonuçta, DYY'nin cari işlemler dengesi üzerinde negatif bir etki yarattığı bulgusu elde edilmiştir.

Mencinger (2008) çalışmasında, AB'ye yeni üye olan ülkeler için 1996-2006 dönemini ele alarak DYY ve cari işlemler dengesi arasındaki etkiyi ortaya koymayı amaçlamıştır. Panel sabit etkiler modeli sonuçlarında, DYY'nin cari açığı azalttığı belirlenmiştir. Yan ve Yang (2008) çalışmalarında, 5 gelişmiş ülke ve 5 de yükselen piyasa ekonomilerinden olmak üzere toplamda 10 ülke için yabancı sermaye girişleri ve cari işlemler dengesi arasındaki nedensellik ilişkisini incelemişlerdir. Ülkelere göre ele alınan dönem verileri farklı alınmıştır. Çalışmada, 1974 ve 2005 yılları arasındaki çeyreklik veriler kullanılmıştır. Analiz sonucunda, incelenen tüm yükselen piyasa ekonomilerinde yabancı sermayeden cari işlemlere doğru nedensellik ilişkisi belirlenmiştir. Gelişmiş ülkelerden ise sadece iki ülkede bu ilişkiye rastlanmıştır.

Razmi (2009) çalışmasında, gelişmekte olan ülkeler için 1970-2005 verileriyle bir genel denge analizi yapmıştır. Analiz sonucunda, DYY'nin ülkelerin cari işlemler dengesi üzerinde negatif yönlü bir etkiye sahip olduğu saptanmıştır. Ehimare (2011), Nijerya ekonomisinde DYY'nin etkisini araştırmıştır. 1980- 
2009 verileri ile farklı analizler yapılmıştır. DYY'nin cari işlemler dengesi üzerindeki etkisini test eden modelleme sonucunda DYY'nin cari işlemler dengesi üzerinde pozitif etki yarattı̆̆ tespit edilmiştir.

Jaffri, Asghar, Mahnaz ve Asjed (2012) çalışmalarında, Pakistan için 1983-2011 dönemini ele alarak DYY ile cari açık arasındaki ilişkiyi ARDL yöntemi ile analiz etmişlerdir. Analiz sonucunda DYY'nin kısa ve uzun dönemde cari işlemler açı̆̆ı üzerinde negatif yönlü bir etki yarattığı ortaya konulmuştur. Siddiqui ve Ahmad (2012), 1976-2005 dönemi verilerini kullanarak Pakistan için DYY ile cari işlemler açığ1 arasındaki ilişkiyi analiz etmişlerdir. Çalışmada kullanılan nedensellik analizleri sonuçlara göre, uzun dönemde DYY'den cari işlemler açığına doğru tek yönlü bir nedensellik ilişkisi belirlenmiştir.

Kaur, Yadav ve Gautam (2012), Hindistan için 1975 ve 2009 dönemini ele alarak ithalat, ihracat, cari açı ve DYY üzerine inceleme yapmışlardır. Cari açık ve DYY arasında uzun dönemli ilişki eşbütünleşme testi ile ortaya konulmuştur. Toda-Yamamoto nedensellik analizi sonucunda ise, DYY'den cari açı̆ğa doğru tek yönlü nedensellik ilişkisi olduğu bulgusuna erişilmiştir. Zafir ve Sezgin (2012) Türkiye için 1992-2011 yılları çeyrek dönemlik veriler ile cari açığın finansmanında DYY'nin etkisini araştırmışlardır. Eşbütünleşme ve nedensellik analizlerinin yapıldığı çalışmada DYY ve cari açık arasında uzun dönemli bir ilişki tespit edilmiştir. Uzun dönem parametrelerin tahmini sonucunda ise DYY'deki artışın cari açığı negatif yönlü etkilediği sonucuna ulaşılmıştır. Ayrıca analizde bu iki değişken arasında çift yönlü nedensellik ilişkisi bulgusuna da ulaşılmıştır.

Saluja, Bhatia ve Patel (2013), DYY ve cari açı ile DYY ve sermaye hesabı arasındaki ilişkiyi 1991-2012 dönemi verileriyle Hindistan için araştırmışlardır. Çalışmada kullanılan panel eşbütünleşme testi sonuçları değişkenler arasında uzun dönemli bir ilişkinin varlığını göstermiştir. Ayrıca, DYY ile cari açık arasında negatif yönlü bir ilişki tespit edilmiştir. Akbaş, Şentürk ve Sancar (2013) çalışmalarında, G7 ülkeleri için cari işlemler ve doğrudan yabancı yatırımlar arasındaki ilişkiyi analiz etmişlerdir. Panel eşbütünleşme ve panel nedensellik analizlerinin yapıldığı çalışmanın dönemi 1990-2011 yılları arasıdır. DYY, cari açık ve ekonomik büyüme gibi değişkenlerin kullanıldığı çalışmada değişkenler arasında uzun dönemli ilişki tespit edilmiştir. Cari açık ve DYY açısından nedensellik ilişkisi tespitinde kullanılan Dimitrescu-Hurlin nedensellik analizi sonuçlarında, DYY'den cari açığa doğru tek yönlü nedensellik ilişkisi belirlenmiştir.

Değer ve Ay (2013), 1990-2011 dönemi verileri ile orta üst gelirli 30 GOÜ için DYY ile cari işlemler bilançosundaki değişmeler arasındaki ilişkiyi analiz etmişlerdir. Çalışmada dinamik panel nedensellik testi kullanılmıştır. Analiz sonucunda, DYY'ler ile cari işlemler bilançosu arasında çift yönlü nedensellik ilişkisi saptanmışır. Mercan ve Yurttançıkmaz (2013), 1991-2013 dönemini ele aldıkları çalışmada Türkiye için doğrudan yabancı yatırımların cari işlemler açığı üzerindeki etkisini analiz etmişlerdir. ARDL sınır testi analizinin yapıldığı çalışmada, doğrudan yabancı yatırımların cari açığı düşürücü yönde etki yarattığı belirlenmiştir. Arabi (2014), 1972-2011 dönemi verileriyle Sudan için cari açık ve DYY arasındaki ilişkiyi incelemiştir. Çalışmada ekonometrik zaman serisi VECM yaklaşımı ile kısa ve uzun dönem analiz yapılmıştır. Analiz sonucunda, iki değişken arasında uzun dönemli ilişkinin varlığı saptanmıştır. Ancak, cari açık üzerinde DYY'nin etkisi zayıf olarak tespit edilmiştir.

Göçer ve Peker (2014) çalışmalarında, Türkiye, Çin ve Hindistan için DYY'nin cari işlemler dengesi üzerindeki etkilerini analiz etmişlerdir. Çalışmada, 1980-2011 dönemi verileriyle panel eşbütünleşme ve dinamik en küçük kareler yöntemi kullanılarak analiz yapılmıştır. Analiz sonuçlarına göre, DYY'deki artış cari işlemler açığını azaltmaktadır. Rahman ve Bristy (2015), SAARC ülkeleri için DYY'nin makroekonomik etkilerini araştırmışlardır. 2002-2012 yıllarını kapsayan çalışmada korelasyon ve regresyon analizleri yapılmıştır. Çalışmada, DYY'deki artışın cari açık dengesine olumlu katkı yaptığı sonucuna ulaşılmıştır.

Oeking ve Zwick (2015), 23 OECD ülkesi için 1990-2013 yılları çeyreklik verilerle cari işlemler hesabı ve finansal sermaye hesabı arasındaki ilişkiyi analiz etmişlerdir. Çalışma sonucunda, cari işlemler hesabının doğrudan yabancı yatırımlar, portföy yatırımları ve diğer yatırımların genelde Granger nedeni olduğu tespit edilmiştir. Ayrıca analiz sonucunda, ekonomide durgunluğun yaşandığı zamanlarda finansal hesap bileşenlerinin cari hesabı finanse ettiği, ekonomide yükselişin olduğu süreçte ise cari hesapta değişim yarattığı belirlenmiştir. Turan ve Karakaş (2016) cari denge ile yabancı sermaye yatırımları arasında bir ilişki olup olmadığını Türkiye için 1998-2014 verileri ile analiz etmişlerdir. Çalışmada kullanılan Toda-Yamamoto ve Hatemi-J nedensellik testleri sonucunda, Türkiye' de finans hesabından cari işlemler dengesine doğru tek yönlü nedensellik ilişkisi saptanmıştır.

Kesgingöz ve Karataş (2016) çalışmalarında, Türkiye için 1992-2015 verilerini kullanarak panel Granger nedensellik analizi yapmışlardır. DYY ve cari açık arasındaki nedensellik ilişkisinin araştırıldığı çalışmada, ele alınan dönem 1992-2001 ve 2002-2015 şeklinde ikiye ayrılmıştır. Analiz sonucunda her iki dönemde için cari açıktan DYY'ye doğru tek yönlü nedensellik ilişkisi olduğu sonucu tespit 
edilmiştir. Yalta ve Bayraktar Sağlam (2016), gelişmekte olan ülkeler için yabancı sermaye akımları ve cari işlemler arasındaki karşılıklı ilişkileri test etmişlerdir. Dinamik panel nedensellik testinin kullanıldığı çalışmanın dönemi 1980-2009 arasıdır. Çalışma neticesinde, DYY'nin cari açığın nedeni olduğu bulgusuna ulaşılmıştır.

Çeştepe, Abasız ve Şık (2018) çalı̧̧malarında, BRICS-T ülkeleri için bir nedensellik analizi yapmışlardır. 2005-2017 döneminin çeyreklik verilerle analiz edildiği çalışmada, Çin haricindeki diğer ülkelerde DYY'nin cari açığı etkilediği sonucuna ulaşılmıştır. Sadaf ve Amin (2018), 1980-2015 dönemini ele aldıkları çalışmayı Bangladeş için gerçekleştirmişlerdir. Granger nedensellik analizinden faydalanılan çalışmada, DYY ve cari açık arasındaki ilişki analiz edilmiştir. Analiz sonucunda, DYY'den cari açığa doğru tek yönlü nedensellik ilişkisi saptanmıştır.

Keskin (2019) çalışmasında, 1998-2018 dönemi çeyreklik verileri ile Türkiye için bir analiz yapmıştır. Analizde, finans hesabı ve cari işlemler hesabı arasındaki nedensellik ilişkileri incelenmiştir. Analiz sonucunda, cari işlemler hesabından finans hesabına doğru tek yönlü nedensellik ilişkisi tespit edilmiştir. Alt bileşenler açısından bakıldığında ise, cari işlemlerden doğrudan yabancı yatırımlara doğru tek yönlü nedensellik olduğu sonucuna ulaşılmıştır.

Oke ve Adigun (2020) çalışmalarında, Nijerya için ARDL sınır testi yaklaşımı kullanarak cari işlemler dengesi üzerinde sermaye girişlerinin etkisini ortaya koymuşlardır. Yapılan analiz ile DYY girişleri ile cari işlemler dengesi arasında negatif yönlü bir ilişki olduğu sonucuna ulaşılmıştır. Aimon, Kurniadi ve Sentosa (2020), düşük gelirli ASEAN ülkeleri için cari açık ve DYY arasındaki nedensellik ilişkisini incelemişlerdir. Değişkenler arasındaki ilişkiyi incelemek için eşanlı denklem modeli yaklaşımı kullanılmış ve dönem olarak 2000-2017 yılları arası esas alınmıştır. Analiz sonucunda, ilk olarak cari açığın DYY'den negatif yönlü etkilendiği tespit edilmiştir. İkinci olarak DYY'nin cari işlemler dengesinden pozitif yönlü etkilendiği sonucuna ulaşılmıştır. Üçüncü olarak ise bu iki değişken arasında güçlü bir nedensellik ilişkisi belirlenmiştir.

\section{Veri seti ve model}

Literatürde, gerek cari işlemler açığı gerekse doğrudan yabancı yatırımlar ile ilgili çok sayıda çalışma mevcut olmasına rağmen iki gösterge arasındaki ilişkileri inceleyen çalışma sayısı çok fazla değildir. MIST (Meksika, Endonezya, Güney Kore ve Türkiye) ülkeleri için yapılan bir çalışmaya ise rastlanmamıştır. Bu nedenle çalışmada, MIST ülkeleri özelinde cari açı ile doğrudan yabancı yatırımlar arasındaki ilişkinin ampirik olarak analiz edilmesi hedeflenmiştir. Çalışmada, cari açık ve doğrudan yabancı sermayeyi temsilen kullanılan değişkenler ile kontrol değişkeni olarak analize dâhil edilen ticari açıklık değişkenine ilişkin bilgiler Tablo 1'de verilmektedir.

Tablo 1: Veri Seti

\begin{tabular}{ccc}
\hline Değişkenler & Semboller & Kaynak \\
\hline Cari İşlemler Dengesi (\%GDP) & CAB & Dünya Bankası \\
\hline Doğrudan Yabancı Sermaye Girişleri (\% GDP) & FDI & Dünya Bankası \\
\hline Ticari Açıklık (İhracat+ithalat /GSYH yüzdesi olarak) & TO & Dünya Bankası \\
\hline
\end{tabular}

Çalışmada cari açık, doğrudan yabancı yatırım ve ticari açıklık göstergelerine ilişkin veriler Dünya Bankası'nın internet veri tabanından ulaşılmıştır (https://databank.worldbank.org/source/worlddevelopment-indicators). Panel eş bütünleşme ve panel veri analizi yönteminin kullanıldığı çalışmada, uzun dönem katsayılarının tahmin edilmesinde Denklem 1'de verilen modelden yararlanılmıştır. Ekonometrik model analizi, Stata 15 ve Eviews 9 paket programları kullanılarak yapılmıştır.

$$
C A B_{i t}=\propto_{0}+\beta_{1} F D I_{i t}+\beta_{2} T O_{i t}+\varepsilon_{i t}
$$

Denklem 1'de, CAB bağımlı değişkeni, FDI bağımsız değişkeni, TO kontrol değişkeni, a sabit katsayısını, $\beta$ eğim katsayısını ve $\varepsilon$ hata terimini ifade etmektedir. Burada $t$, zamanı ve $i$ ise ülkeyi göstermektedir.

\section{Yöntem ve bulgular}

1990-2019 döneminin ele alındığı çalışmada ilk olarak modele ilişkin yatay kesit bağımlılığı ve homojenlik testleri yapılmıştır. Daha sonra ise serilerin durağanlıklarına ilişkin birim kök testleri gerçekleştirilmiştir. Seriler arasında uzun dönemli ilişkinin varlığını saptayabilmek için panel 
eşbütünleşme testlerinden faydalanılmıştır. Uzun dönemli ilişkinin belirlenmesi sonrasında ise uzun dönem katsayıları tespit edilmiştir.

\section{Yatay kesit bağımlılı̆̆ı ve homojenlik testleri}

Panel veri analizlerinde genellikle regresyon tahmincilerinin varsayımları serinin durağan olduğu şeklindedir. Bu nedenle panel veri analizi gerçekleştirilirken sahte regresyon sorunu ile karşılaşmamak adına durağanlık analizleri gerçekleştirilmektedir. Panel birim kök testleri ile durağanlık sınaması yapılmadan önce iki durumun tespit edilmesi söz konusudur. Bu durumlardan birincisi seriler arası yatay kesit bağımlılı̆̆ının tespitidir. İkincisi ise parametrenin homojenliğinin sınanması durumudur. Yatay kesit bağımlılığının varlığına göre panel birim kök testi ve panel tahmincisi belirlenmektedir. Homojenlik sınaması sonuçları ise panel tahmin yönteminin tercih edilmesinde ön plana çıkmaktadır (Boğa, 2019, s. 367). Literatürde yatay kesit bağımlılığının tespitine ilişkin farklı testler bulunmaktadır. Çalışmadaki söz konusu değişkenlere ait serilerde yatay kesit bağımlılığının varlığını sınayabilmek amaciyla T>N durumunda kullanılabilen Breusch-Pagan (1980) LM testi testinden faydalanılmıştır. Bruesch-Pagan (1980) LM testi $\mathrm{H}_{0}$ hipotezi yatay kesit bağımlılığının olmadığını ifade etmektedir. Bruesch-Pagan (1980) LM test istatistiği Denklem 2'de verilmiştir:

$$
L M_{B P}=T \sum_{i=1}^{N-1} \sum_{j=i+1}^{N} \widehat{\rho}_{i j}^{2}
$$

Denklem 2 'de $\hat{\rho}_{i j}^{2}$ ile i. ve j. birimlerin kalıntıları arasındaki korelasyon katsayısı ifade edilmektedir (Yerdelen Tatoğlu, 2018, s. 227). Tablo 2'de, testlere ilişkin sonuçlar verilmektedir.

Tablo 2: Breusch-Pagan LM Test Sonuçları

\begin{tabular}{ccc}
\hline Değişken & Test İstatistiği & Olasıllkk \\
\hline CAB & 7.776560 & 0.2549 \\
\hline FDI & 21.44488 & $0.0015^{* * *}$ \\
\hline TO & 60.08221 & $0.0000^{* * *}$ \\
\hline Eşbütünleşme Denklemi & 17.720 & $0.0070^{* * *}$ \\
\hline
\end{tabular}

Not: ***\%1 düzeyinde anlamlıdır.

Kaynak: Yazar tarafından üretilmiştir.

Tablo 2 incelendiğinde, Bruesch-Pagan LM testine göre FDI ve TO serilerinde olasılık değeri 0.05 'ten küçük olduğu için yatay kesit bağımlılığının olmadığını ifade eden $\mathrm{H}_{0}$ hipotezi reddedilmektedir. Dolayısıyla bu serilerde yatay kesit bağımlılı̆̆ kabul edilmektedir. Ayrıca model için de olasılık değerine bakıldığında yatay kesit bağımlığının varlığının kabul edildiği görülmüştür. Bu sebeple durağanlık analizleri yapılırken ikinci kuşak birim kök testlerinin kullanılması tercih edilmiştir.

Panel veri analizinde parametrenin homojenliğinin test edilmesinde Pesaran ve Yamagata (2008) tarafından geliştirilen delta $(\Delta)$ testleri kullanılabilmektedir. Homojenliğin belirlenmesinde sunulan iki farklı delta testi Denklem 3 ve 4' de gösterilmektedir (Pesaran ve Yamagata, 2008, ss. 54-55):

$$
\begin{aligned}
& \tilde{\Delta}=\sqrt{N}\left(\frac{N^{-1} \tilde{s}-k}{\sqrt{2 k}}\right) \\
& \tilde{\Delta}_{a d j}=\sqrt{N}\left(\frac{N^{-1} \tilde{s}-E\left(\widetilde{Z}_{i t}\right)}{\sqrt{\operatorname{Var}}\left(\tilde{Z}_{i t}\right)}\right)
\end{aligned}
$$

Eşitliklerde $\mathrm{N}$ ile yatay kesit sayısı, $\mathrm{S}$ ile Swamy test istatistiği, $\mathrm{k}$ ile açılayıcı değişken sayısı gösterilmektedir. Bu teste ilişkin $\mathrm{H}_{0}$ hipotezi eğim katsayılarının homojen olduğu biçimindedir. Eğer $\mathrm{H}_{0}$ hipotezinin reddedilirse eğim katsayılarının heterojenliği belirlenmiş olur. Tablo 3 'de, delta testlerine ilişkin sonuçlar sunulmaktadır.

Tablo 3: Homojenlik Testi

\begin{tabular}{ccc}
\hline Test & Test istatistiği & Olasılık \\
\hline Delta Tilde & 4.013 & $0.0000^{* * *}$ \\
\hline Delta Tilde adj. & 4.311 & $0.0000^{* * *}$ \\
\hline
\end{tabular}

Not: ***\%1 düzeyinde anlamlıdır.

Kaynak: Yazar tarafından üretilmiştir. 
Tablo 3 incelendiğinde delta test sonuçlarına göre serilerin $\mathrm{H}_{0}$ hipotezinin reddedildiği dolayısıyla heterojenliğin tespit edildiği görülmektedir.

\section{Panel birim kök testleri}

Literatürde durağanlık analizleri yapılırken birinci ve ikinci kuşak birim kök testleri ile karşılaşılmaktadır. Hangi kuşak birim kök testinin tercih edileceğinin belirlenmesinde serilerin yatay kesit bağımlılığının olup olmadığının dikkate alınması gerekmektedir. Bu çalışmada yapılmış olan Bruesch-Pagan LM testi sonuçları yatay kesit bağımlılığının varlığı göstermekteydi. Bu nedenle birim kök testi sınamasında ikinci kuşak birim kök testlerinden Pesaran (2007) tarafından geliştirilen "yatay kesit genişletilmiş Dickey-Fuller" (CADF) testi tercih edilmiştir. Pesaran panel birim kök sınamasında genişletilmiş Dickey-Fuller (ADF) regresyonunun gecikmeli yatay kesit ortalamaları kullanılmaktadır. Temel CADF regresyonu Denklem 5'te gösterilmektedir (Yerdelen Tatoğlu, 2018, s. 85):

$$
\Delta y_{i t}=\propto_{i}+\rho_{i}^{*} Y_{i, t-1}+d_{0} \bar{Y}_{t-1}+d_{i} \Delta \bar{Y}_{t}+\varepsilon_{i t}
$$

Durağanlığın test edilmesinde $\mathrm{H}_{0}$ hipotezi $\mathrm{H}_{0}=p_{i}=0$ biçimindedir. Eğer hipotez reddedilirse serilerin durağan olduğu tespit edilmiş olur. Tablo 4' de, panel birim kök test sonuçları verilmektedir.

Tablo 4: Pesaran CADF Birim Kök Testleri

\begin{tabular}{cclll}
\hline & \multicolumn{2}{c}{ Sabit } & \multicolumn{2}{c}{ Sabit+trend } \\
\hline & İstatistik & Olasılık & İstatistik & Olasılık \\
\hline CAB & -2.136 & 0.219 & -2.590 & 0.274 \\
\hline FDI & -2.773 & $0.018^{* *}$ & -2.578 & 0.282 \\
\hline TO & -1.293 & 0.832 & -2.606 & 0.262 \\
\hline$\Delta$ CAB & -4.349 & $0.000^{* * *}$ & -4.475 & $0.000^{* * *}$ \\
\hline$\Delta$ FDI & -5.284 & $0.000^{* * *}$ & -5.391 & $0.000^{* * *}$ \\
\hline$\Delta$ TO & -3.768 & $0.000^{* * *}$ & -3.698 & $0.000^{* * *}$ \\
\hline
\end{tabular}

Not: ${ }^{* * * \% 1}$ ve ${ }^{* * \% 5}$ anlamlılık düzeyini göstermektedir.

Kaynak: Yazar tarafından üretilmiştir.

Tablo 4'deki Pesaran CADF panel birim kök test sonuçlarına göre serilerin sabitli gösterimde FDI değişkeni hariç seviyede birim kök içerdiği ifade edilebilir. Serilerin farkı alındığında ise durağanlığın tespit edildiği görülmektedir. Serilerin aynı seviyede durağanlıkları tespit edildiği için aralarında uzun dönemli bir ilişkinin var olup olmadığı test edilebilir. Bu nedenle bir sonraki aşamada panel eşbütünleşme ilişkisi analiz edilmektedir.

\section{Panel eşbütünleșme testi}

Çalışmada eşbütünleşme ilişkisi Westerlund eşbütünleşme testi ile araştırılmıştır. Westerlund (2007), hata düzeltme modeline dayanan 4 farklı panel eşbütünleşme testi ile eşbütünleşme ilişkisinin test edilmesini öne sürmektedir. Bu testlerden iki tanesi $\left(G_{t} v e G_{a}\right)$ grup ortalama istatistiklerini iki tanesi ise panel istatistiklerini $\left(\mathrm{P}_{t}\right.$ ve $\left.\mathrm{P}_{\mathrm{a}}\right)$ temsil etmektedir. Bu testlerin özünde, her bir birimin kendi hata düzeltmesine sahip olup olmadığına karar verilmesi sonucunda eşbütünleşme ilişkisinin araştırılması söz konusudur. "Ho hipotezi=Hata düzeltme yoktur" biçimindedir. Eğer bu hipotez reddedilirse eşbütünleşme yoktur hipotezi de reddedilmiş olur (Yerdelen Tatoğlu, 2018, ss. 200-201). Modelde yatay kesit bağımlılığı tespit edildiği Westerlund (2007) panel eşbütünleşme testinin, dirençli bootstrapt süreci ile elde edilmesi gerekmektedir. Bu koşulu içeren analiz ile elde edilmiş eşbütünleşme test sonuçları Tablo 5'de sunulmuştur.

Tablo 5: Westerlund Eşbütünleşme Testleri

\begin{tabular}{ccccc}
\hline İstatistik & Değer & Z-Değeri & Olasılık & Bootstrapt Olasılık \\
\hline Gt & -4.129 & -4.547 & 0.000 & $0.000^{*}$ \\
\hline Ga & -19.139 & -3.193 & 0.001 & $0.000^{*}$ \\
\hline $\mathbf{P t}$ & -8.784 & -5.189 & 0.000 & $0.000^{*}$ \\
\hline $\mathbf{P a}$ & -20.705 & -5.308 & 0.000 & $0.000^{*}$ \\
\hline
\end{tabular}

Not: Bootstrap olasılık değerleri 100 Bootsrap değeri ile elde edilmiştir. Gecikme ve öncül seviyeleri 1 alınmıştır. Kaynak: Yazar tarafından üretilmiştir. 
Tablo 5 incelendiğinde, Westerlund eşbütünleşme test sonuçlarına göre, hem grup hem de panel istatistiklerini gösteren eşbütünleşme test sonuçları eşbütünleşme yoktur $\mathrm{H}_{0}$ hipotezini reddedmektedir. $\mathrm{Bu}$ da, uzun dönemde değişkenler arasında anlamlı bir ilişki olduğunu göstermektedir. Değişkenlerin uzun dönemde aralarında ilişkisi olduğu tespit edildikten sonra bu ilişkinin katsayılarının tespit edilmesi aşamasına geçilmiştir.

\section{Uzun dönem katsayılarının tespiti}

Bu aşamada Pedroni (2001) tarafından geliştirilen ortalama grup dinamik en küçük kareler (DOLSMG) yöntemi kullanılacaktır. Bu tahminci yatay kesit ortalamalardan fark alarak dönüştürüp tüm panel için yatay kesit bağımlılığa dirençli tahminler elde edilmesine imkân tanımaktadır. Bunun yanı sıra panel model tahmini her birim için elde edilecek tahminlerin ortalamalarının alınmasıyla saptanmaktadır (Özcan, 2021, s. 167). Diğer bir deyişle DOLSMG tahmincisi heterojen modellerde kullanılmaktadır. Çalışmada da hem yatay kesit bağımlılığı hem de heterojenlik tespit edildiği için modelin uzun dönem katsayılarının belirlenmesinde bu tahminci tercih edilmiştir. Tablo $6^{\prime}$ da panel DOLSMG sonuçları verilmiştir.

Tablo 6: Panel DOLSMG Tahmin Sonuçları

\begin{tabular}{|c|c|c|c|c|}
\hline \multirow{2}{*}{ Ülkeler } & \multicolumn{2}{|c|}{ FDI } & \multicolumn{2}{|c|}{ TO } \\
\hline & Katsayı & t-istatistiği & Katsayı & $t$-istatistiğ $i$ \\
\hline Meksika & -1.458 & $-2.726^{*}$ & -0.0137 & -0.3102 \\
\hline Endonezya & -1.214 & $-3.181^{*}$ & 0.05405 & $2.041^{*}$ \\
\hline G. Kore & 0.2119 & 0.3012 & 0.1595 & $4.165^{*}$ \\
\hline Türkiye & -2.443 & $-2.506^{*}$ & 0.2533 & $2.083^{*}$ \\
\hline Panel & -1.226 & $-4.056^{*}$ & 0.1133 & $3.989^{*}$ \\
\hline
\end{tabular}

Not: *\%5 anlamlllık düzeyini göstermektedir.

Kaynak: Yazar tarafından üretilmiştir.

Tablo 6' da değişkenler arasındaki uzun dönem tahminleri incelendiğinde panelin bütünü için hem FDI hem de TO değiş̧keninin cari açı ile ilişkisinin literatürde beklenildiği şekilde olduğu görülmektedir. FDI'deki değişmelerin cari açığı negatif yönde etkilediği tespit edilmiştir. Panel DOLSMG tahmincisine göre, panel genelinde FDI'deki 1 birimlik artış cari açığı 1.22 birim azaltmaktadır. Bu da FDI'nin cari açığın finansmanında önemli bir etken olduğu beklentisini destekleyen bir sonuçtur. Panel DOLSMG tahmin sonuçları ülke bazında değerlendirildiğinde, FDI'nın cari açık üzerindeki etkisi için Güney Kore hariç diğer ülkelerde katsayının negatif ve istatistiki olarak anlamlı olduğu belirlenmiştir. MIST ülkeleri içinde esneklik katsayısı en yüksek olan ülke 2.44'lük katsayı değeri ile Türkiye' dir. Bu oran Meksika'da 1.45 iken Endonezya'da 1.21 olarak tespit edilmiştir. Bu katsayılar doğrudan yabancı yatırım girişlerindeki 1 birimlik artışın cari açığı Türkiye'de 2.44, Meksika'da 1.45 ve Endonezya'da ise 1.21 birim azalttığını ifade etmektedir. Daha önce belirtildiği üzere bu durum FDI ile CAB arasındaki ilişkinin önemini bir kez daha ortaya koymaktadır. Bu nedenle ülkelerin FDI girişlerini teşvik edecek yönde politikalar izlemelerinin önemi MIST ülkeleri özelinde ortaya konulmuştur.

Analize kontrol değişkeni olarak dâhil edilen TO ile CAB arasındaki ilişkinin aynı yönlü olması beklenmektedir. Tablo 6 incelendiğinde panel genelinde bu ilişkinin katsayısının beklenildiği gibi pozitif ve istatistiki olarak anlamlı olduğu görülmektedir. DOLSMG sonuçlarına göre, ticari açıklıktaki bir birimlik artış cari açığı 0.11 birim arttırmaktadır. Dolayısıyla ticari açılığın artması ile beklenen birçok avantaj yanında bunun cari açık sorununa neden olabileceği de dikkate alınmalı ve buna ilişkin tedbirler alınmalıdır. Panel DOLSMG tahmin sonuçları da yine ülke bazında değerlendirildiğinde, TO'nun cari açık üzerindeki etkisinin Meksika hariç tüm ülkelerde pozitif yönlü etki yarattığı ve istatistiki olarak anlamlı olduğu sonucuna ulaşılmıştır. DOLSMG tahmin sonuçlarına göre Türkiye için TO' daki 1 birimlik artış cari açığı 0.25 birim arttırmaktadır. G. Kore' de TO'daki 1 birimlik artış cari açığı 0.15 birim arttırırken bu oran Endonezya' da 0.05'tir. Dolayısıyla, MIST ülkeleri içinde TO'daki artışın cari açık üzerindeki etkisinin en fazla hissedildiği ülke olarak Türkiye'nin, en az etkilediği ülke olarak ise Endonezya'nın tespit edildiği sonucuna ulaşılmıştır. Elde edilen bulgular genel olarak değerlendirildiğinde ise cari işlemler açığının gerek yabancı sermaye yatırımlarına gerekse de ticari açıklığa karşı duyarlı olduğu ifade edilebilir. 


\section{Sonuç}

Ülkelerin ekonomi politikalarında liberalleşmenin etkilerinin artmasıyla birlikte birçok gösterge ön plana çıkmıştır. Ülkelerin üretimlerini daha fazla arttırabilmek amacıyla ihtiyaç duydukları hammadde teminini sağlarken karşılaştıkları cari açık bu göstergelerden bir tanesidir. Cari açık sorunu yaşayan ülkelerin bu sorunu telafi edebilmesinde ise DYY'ler önemli rol oynamaktadır. Bu iki değişken arasındaki ilişkinin varlı̆̆ının tespit edilmesi için çalışmada, MIST ülkeleri özelinde, 1990-2019 dönemi verileriyle bir analiz yapılmıştır.

Çalışmada öncelikle yatay kesit bağımlılığı ve homojenliğe ilişkin testler yapılmıştır. Yapılan testler sonrasında hem yatay kesit bağımlılığı hem de heterojenliğin varlığı sonucuna ulaşılmıştır. Bu çerçevede analizde kullanılacak testlere karar verilmiş̧ir. Serilerin durağanlığını tespit etmek için ikinci kuşak birim kök testlerinden CADF panel birim kök testi yapılmıştır. Serilerin birinci farkında durağan olduğu belirlendikten sonra, değişkenler arasında uzun dönemli bir ilişkinin olup olmadığının tespiti için panel eşbütünleşme analizi yapılmıştır. Westerlund eşbütünleşme testi ile elde edilen 4 farklı istatistik değişkenler arasında uzun dönemli ilişkinin varlığını ortaya koymuştur. Bu nedenle uzun dönem katsayılarının belirlenmesi aşamasına geçilmiştir. Bu aşamada yatay kesit bağımlılığı ve heterojenliğe izin veren DOLSMG tahmincisinden yararlanılmıştır. DOLSMG tahmincisine göre, MIST ülkeleri için panel genelinde doğrudan yabancı yatırımların cari açığı negatif yönlü etkilediği tespit edilmiştir. Bu etkinin katsayısı 1.22 olarak belirlenmiş̧ir. Bunun anlamı FDI girişlerindeki 1 birimlik artışın cari açı̆̆ı 1.22 birim azalttığı biçimindedir. Ülkeler bazında bakıldığında ise G. Kore hariç tüm ülkelerde bu ilişkinin yakalandığı görülmüştür. Ayrıca MIST ülkeleri arasında Türkiye için DYY'nin cari açık üzerinde en fazla etki yarattığı ülke olduğu sonucuna da ulaşılmıştır. DYY'nin cari açığı negatif yönlü etkilemesi literatürle de örtüşmektedir. Literatürde benzer sonuçlara ulaşan çalışmalar; Liuyong ve Yanping (2007), Mencinger (2008), Razmi (2009), Jaffri, Asghar, Mahnaz ve Asjed (2012), Göçer ve Peker (2014), Çeştepe, Abasız ve Şık (2018) ve Oke ve Adigun' un (2020) çalışmaları olarak sıralanabilir. Analizde ayrıca ticari açıklık ve cari açık ilişkisi de belirlenmiştir. Bu ilişkinin yönü pozitif olarak tespit edilmiştir. Bu durum da teorik beklentilerle uyumludur. Ticari açıklık seviyesinin yükselmesi ülkelerde cari açık oranının artmasına neden olmaktadır. Analizde de panel genelinde TO' daki 1 birimlik artışın cari açı̆̆ı 0.11 birim arttırdığı sonucuna ulaşılmıştır. Ülkeler bazında ise Meksika hariç diğer incelenen ülkelerde katsayılar beklenildiği gibi pozitif ve istatistiki olarak anlamlı tespit edilmiştir. Genel bir değerlendirme yapıldığında ise cari açığın hem FDI'daki hem de TO'daki değişmelerden etkilendiği söylenebilir.

Analiz bulguları çerçevesinde, cari açı ve DYY arasında önemli bir etkileşim olduğu sonucuna ulaşılmıştır. Dolayısıyla cari açı sorunu yaşayan ülkeler için DYY girişlerinin önemi ortaya konulmuştur. Bu açıdan bakıldığında, DYY'lerin ülkeye girişinin artırılması için gereken önlemlere bir kez daha dikkat çekilmesi gerektiği görülmektedir. DYY'ler gittikleri ülkelerde siyasi ve ekonomik istikrarı önemsemektedirler. Bu nedenle, DYY girişlerini arttırabilmek için bu istikrar ortamının sağlanması adına gereken reformların gerçekleşmesi yönünde ciddi adımlar atılmalıdır. Ayrıca, politika yapıcılar DYY girişlerinde yatırımcıyı teşvik edecek politikaları ön plana çıkarmalıdır. Bunun yanı sıra bürokratik işlemlerin azaltılması adına hukuki düzenlemelerin de gerçekleştirilmesi gerekmektedir.

\section{Hakem Değerlendirmesi / Peer-review:}

Dış bağımsız

Externally peer-reviewed

\section{Çıkar Çatışması / Conflict of interests:}

Yazar(lar) çıkar çatışması bildirmemiştir.

The author(s) has (have) no conflict of interest to declare.

\section{Finansal Destek / Grant Support:}

Yazar bu çalışma için finansal destek almadığını beyan etmiştir.

The author declared that this study has received no financial support. 


\section{Kaynakça / References}

Aimon, H., Kurniadi, A. P. ve Sentosa, S. U. (2020). Determinants and causality of current account balance and foreign direct investment: Lower middle income countries in ASEAN. 3rd International Research Conference on Economics and Business, KnE Social Sciences, 10-22.

Akbaş, Y. E., Şentürk, M. ve Sancar, C. (2013). Testing for causality between the foreign direct investment, current account deficit, GDP and total credit: Evidence from G7. Panoeconomicus, 6, 791812.

Arabi, A. M. K. (2014). The impact of foreign direct investment FDI and real GDP on current account: Empirical evidence from Sudan 1972-2011. International Journal of Business and Social Science, 5(8), 109-116.

Bedir, S. ve Soydan, A. (2016). Implications of FDI for current account balance: A panel causality analysis. Eurasian Journal of Economics and Finance, 4 (2), 58-71.

Boğa, S. (2019). Ekonomik karmaşıklık seviyesinin ekonomik büyüme üzerine etkisi: Geçiş ülkeleri için bir panel zaman serisi analizi. Akademik Hassasiyetler, 6 (12), 357-386.

Borensztein, E., Gregoria, J.D. ve Lee, J.W. (1998). How does foreign direct investment affect economic growth?. Journal of International Economics, 45 (1), 115-135.

Çeştepe, H., Abasız, T. ve Şık, A. (2019). Cari açı̆̆ın finansmanı ve doğrudan yabancı yatırımlar: BRICST ülkeleri için nedensellik analizi. Uluslararası Yönetim İktisat ve İşletme Dergisi, 15 (3), 660-672.

Değer, Ö. ve Ay, D. (2013). Gelişmekte olan ülkelerde doğrudan yabancı yatırımlar ve cari işlemler arasındaki nedensel ilişkiler (1990-2011). Paradoks Ekonomi Sosyoloji ve Politika Dergisi, 9 (2), 5-22.

Ehimare, O. A. (2011). Foreign direct investment and its effect on the Nigerian economy. Business Intelligence Journal, 4 (2), 253-261.

Erdil Şahin B. (2011). Türkiye'nin cari açık sorunu. Ekonomi Bilimleri Dergisi, 3 (2), 47-56.

Fry, M., Claessens, C. A., Burridge, P. ve Blanchet, M. (1995). Foreign direct investment other capital flows and current account deficits. Policy Research Working Paper, 1527, World Bank.

Güllü, M. ve Yakışık, H. (2017). Karbon emisyonu ve enerji tüketimin büyüme üzerindeki etkileri: MIST ülkeleri karşılaştırması. Sosyo Ekonomi Dergisi, 25 (32), 239-253.

Göçer, İ. ve Peker, O. (2014). Yabancı doğrudan yatırımların cari işlemler dengesi üzerinden etkileri: Türkiye, Çin ve Hindistan örnekleminde çoklu yapısal kırılmalı eşbütünleşme analizi. Yönetim ve Ekonomi Dergisi, 21 (1), 87-116.

Jaffri, A., Asghar, N., Mahnaz, M. A. ve Asjed, R. (2012). Foreing direct investment and current acoount balance of Pakistan. Pakistan Economic and Social Review, 50 (2), 207-222.

Kaur, M., Yadav, S. S. ve Gautam, V. (2012). Foreign direct investment and current account deficit-a causality analysis in context of India. Journal of International Business and Economy, 13 (2), 85-106.

Kesgingöz, H. ve Karataş, A. R. (2016). Yabancı sermaye yatırımları ile cari işlemler açığı ilişkisi ve cari işlemler açı̆̆ için politika önerileri. İnsan ve Toplum Bilimleri Araştırmaları Dergisi, 5 (3), 597-610.

Keskin, A. (2017). Türkiye'de cari açık sorunu ve açığın finansman yapısı: 1989- 2015 dönemi analizi. Amme İdaresi Dergisi, 50 (3), 9-125.

Keskin, N. (2019). Türkiye' de cari işlemler hesabı ile finans hesabı arasındaki nedensellik ilişkisi. İzmir İktisat Dergisi, 34 (2), 279-297.

Liuyong, Y. ve Yanping, Z. (2007). Empirical analysis of the Impact of FDI on China's Balance of Payments, International Conference on Wireless Communications, Networking and Mobile Computing Shanghai, China.

Mencinger, J. (2008). Direct and indirect effects of FDI on current account. International Centre For Economic Research, Working Paper, 16, 1-21.

Mercan, M. ve Yurttançıkmaz, Z. Ç. (2013). Doğrudan yabancı yatırımlar-cari işlemler açığı ilişkisi: Türkiye için ampirik bir analiz. Bankacılar Dergisi, 87, 57-78.

Oeking, A. ve Zwick, L. (2015). On the relation between capital flows and the current account, RUHR Economic Papers, 565, 1-24. 
Oke, D. F. ve Adigun A. O. (2020). Capital inflow, trade openness and current account balance in Nigeria. International Journal of Economics, Business and Management Research, 4(12), 40-53.

Özcan M. (2021). Sosyal medya platformlarının hisse senedi piyasalarına etkisi: BIST30 örneği. Gümüşhane Üniversitesi Sosyal Bilimler Enstitüsü Elektronik Dergisi, 12(1), 160-172.

Pedroni, P. (2001). Purchasing power parity tests in cointegrated panels. The Review of Economics and Statistics, 83 (4), 727-731.

Pesaran, M. H. ve Yamagata, T. (2008). Testing slope homogeneity in large panels. Journal of Econometrics, 142 (1), 50-93.

Polat, M. (2019). Doğrudan yabancı yatırımların cari işlemler dengesi üzerindeki etkisi: Türkiye örneği. Avrasya Sosyal ve Ekonomi Araştırmaları Dergisi, 6 (5), 159-170.

Rahman, S. M. Z. ve Bristy, J. F. (2015). Macroeconomic impact of foreign direct investment: A study on SAARC countries. European Journal of Business and Management, 7 (34), 59-70.

Razmi, A. (2009). Does pleasing export-oriented foreign investors help your balance of payments? A general equilibrium analysis. Oxford Economic Papers, 61, 128-149.

Sadaf, B. H. ve Amin, S. B. (2018). Causal relationship between current account deficit and foreign direct investment: An empirical analysis of Bangladesh. World Review of Business Research, 8 (3), 52-60.

Saluja, M. S., Bhatia, N. K. ve Patel, N. (2013). A cointegration and VECM approach in explaining relationship of FDI with current and capital account of India. International Journal of Advance Research in Computer Science and Management Studies, 1 (6), 1-6.

Siddiqui, D. A. ve Ahmad, M. H. (2012). The causal relationship between foreign direct investment and current account: An empirical investigation for Pakistan economy. European Journal of Economics, Finance and Administrative Sciences, 44, 107-116.

Turan, T. ve Karakaş, M. (2016). Cari denge ve finans hesabı ilişkisi: Türkiye için ampirik bir uygulama. Maliye Dergisi, 170, 45-58.

UNCTAD (2020). https://unctadstat.unctad.org/wds/TableViewer/tableView.aspx (10.12.2020).

Yalta, A., Y. ve Sağlam, B. B. (2016). Interaction between capital flows and current account: A dynamic panel causality analysis of emerging market economies. Applied Econometrics and International Development, 16 (2), 25-32.

Yan, H. D. ve Yang, C.I. (2008). Foreign capital inflows the current account imbalance: Which causality direction?. Journal of Economic Integration, 23 (2), 434-461.

Yerdelen Tatoğlu, F. (2018). Panel zaman serileri analizi. İstanbul: Beta Basım Yayım.

Zafir, C. Z. ve zafirSezgin, F. H. (2012). Analysis of the effect of foreign direct investment on the financing of current account deficits in Turkey. International Journal of Business and Social Science, 3 (10), 68-78.

Westerlund, J. (2007). Testing for error correction in panel data. Oxford Bulletin Of Economics And Statistics, 69 (6), 709-747.

World Bank (2020). https://databank.worldbank.org/source/world-development-indicators (05.12.2020). 